\title{
RELATOS DE EXPERIENCIA, SABER PEDAGÓGICO Y RECONSTRUCCIÓN DE LA MEMORIA ESCOLAR
}

RESUMEN: El artículo explora las potencialidades teóricas, metodológicas y políticas de la documentación narrativa de experiencias pedagógicas como dispositivo de investigaciónformación-acción entre docentes y modalidad de trabajo colaborativo orientado a la reconstrucción de la memoria pedagógica de la escuela y al cambio educativo. Para ello, propone una mirada pedagógica de las escuelas, los docentes y el currículum, vincula en términos teóricos la narrativa docente, la memoria pedagógica y el currículum en acción, presenta argumentos a favor del diseño de formas de documentación pedagógica alternativas a las dominantes, pondera los relatos de experiencias pedagógicas como otra manera de nombrar el mundo escolar, se interroga e identifica potencialidades críticas de la estrategia, pone en consideración una definición amplia de saber pedagógico e imagina algunas implicancias intelectuales y políticas de la difusión de estas modalidades alternativas de producción de saber pedagógico, formación entre pares e intervención política en el campo pedagógico.

Palabras-clave: Relatos de Experiencia; Saber Pedagógico; Memoria Escolar.

\section{STATEMENTS OF EXPERIENCE, PEDAGOGICAL KNOWLEDGE AND RECONSTRUCTION OF THE SCHOOL MEMORY}

ABSTRACT: The article explores the methodological, theoretical and political potentialities of the narrative documentation of pedagogical experiences as an instrument of educational action research among teachers and as a modality of collaborative work orientated to the reconstruction of the pedagogical memory of the school and to the educational change. Thus, it proposes a pedagogical view of the schools, the teachers and the curriculum, connects in theoretical terms the teacher's narrative, the pedagogical memory and the curriculum in action, presents arguments in favor of the drawing of alternative forms of pedagogical documentation to the dominant ones, shows the statements of pedagogical experiences as another way of naming the school world, asks and identifies critical potentialities of strategy, puts in consideration a wide definition of pedagogical knowledge and imagines some intellectual and political implications of the diffusion of these alternative modalities to produce pedagogical knowledge, formation in pairs and political intervention in the pedagogic field.

Keywords: Statements of Experience; Pedagogical Knowledge; School Memory.

\footnotetext{
* Doctor em Educación por la Universidad de Buenos Aires- Argentina; Director y Profesor del Departamento de Ciencias de la Educación de la Facultad de Filosofía y Letras - Universidad de Buenos Aires - Argentina. E-mail: dhsuarez@filo.uba.ar 
Escuelas, docentes y currículum: una mirada pedagógica

La vida cotidiana en las escuelas es peculiar, diversa, policromática. Y a pesar de que se asemeja a la de otras instituciones, una mirada atenta al trajinar permanente de sus habitantes, a la multiplicidad y calidad de tareas e intercambios que se suceden, nos devuelve una imagen diferente a la de otros ámbitos. La sucesión casi sistemática de bullicios y silencios; las formas que adoptan sus tiempos y ritmos; la convivencia negociada de gentes de diferentes generaciones, sexos, culturas y poderes, les dan a las escuelas una tonalidad muy particular que, aún a simple vista, las diferencia de otros espacios sociales. Visitar una escuela como expedicionarios curiosos, transitar como extranjeros sus pasillos; escuchar sorprendidos los matices de la polifonía de voces que se combinan; conversar extrañados con los adultos, niños y adolescentes que eventualmente nos crucemos en la travesía, nos permitiría aproximarnos un poco a lo que tiene de singular la experiencia vivida en el mundo escolar. Nos permitiría comprender la compleja trama de sucesos, objetos y palabras que cargan de sentidos muy específicos el funcionamiento ordinario y la dinámica social de los establecimientos educativos.

Si miramos atentos y extrañados, como lo haría un antropólogo observando una "cultura nativa" diferente a la suya, veríamos que muchas de las cosas que ocurren en los escenarios escolares están vinculadas con aspectos burocráticos y asistenciales; que otras tienen que ver con cuestiones de economía doméstica, con la intendencia y el control de personas y asuntos, con la arquitectura e higiene de los locales. También percibiríamos que otros acontecimientos que tiñen el mundo escolar se relacionan con el afecto y la sensibilidad de quienes viven en él, con el intercambio de sentimientos y significaciones de sus habitantes. Pero si aguzamos todavía un poco más los sentidos, y nos animamos a relacionar lo que vemos y escuchamos en nuestro recorrido con procesos de mayor generalidad, nos daríamos cuenta que la mayor parte de esa variada actividad se vincula con los problemas pedagógicos de la formación subjetiva de las nuevas generaciones, con la transmisión y la recreación culturales y, al mismo tiempo, con los proyectos educativos que muchas veces disputan entre sí para llevar a cabo esos procesos. Asimismo distinguiremos que eso, precisamente, es lo que diferencia esta institución y experiencia sociales de las demás. 
La escuela siempre estuvo y estará afectada por distintas expectativas sociales respecto del sentido social y formativo que pretende otorgársele, así como por las contiendas ideológicas, políticas y pedagógicas que se derivan de ellas. De hecho, los aparatos educativos y las escuelas están regulados por sistemas de normas, dispositivos y mecanismos institucionales que pretenden responder a las aspiraciones públicas que lograron oficializarse como opciones legítimas. Se disponen para ponerlas en marcha, desarrollarlas e inscribirlas en la vida de la gente mientras transcurre sistemáticamente por ellos. Y para hacerlo, seleccionan y traducen a su lógica ciertos fragmentos culturales, y los organizan, jerarquizan y secuencian como contenidos para la enseñanza, generalmente a través de estrategias estructuradas por el Estado y ponderadas por el conocimiento científico-técnico. A esos procesos sociales, políticos y técnicos de selección, legitimación, estructuración y distribución de conocimientos y valores culturales, el lenguaje especializado los denomina comúnmente "currículum escolar" (DA SILVA, 1997).

Lo cierto es que lo que acontece en las escuelas y en cierta medida lo que les sucede a los actores escolares, es algo que está sujeto a escrutinio público y que es objeto de comentarios especializados, investigaciones, evaluaciones, políticas de estado. Debido a la relevancia política que alcanzó la escolarización masiva durante los últimos años, la actividad escolar pasó a ser una actividad necesariamente programada, anticipada a distintos niveles y escalas (PETITAT, 1994). A nivel de los sistemas educativos, las prácticas escolares pretenden ser reguladas por distintos dispositivos de planeamiento y gestión. Los programas y proyectos elaborados por funcionarios políticos y equipos técnicos de administraciones centrales de educación; los diseños curriculares construidos por equipos de especialistas vinculados con ministerios de educación; las planificaciones regionales o inter-escolares diseñadas por supervisores escolares, son sólo algunas expresiones de ellos. La compleja organización y gestión de los modernos y masificados sistemas escolares sólo es posible a partir de la previsión de tiempos, movimientos y acciones, y de la producción y disposición de discursos, técnicas e instrumentos que permitan controlarlos, medirlos, corregirlos, reorientarlos. Aunque a otra escala y nivel, las experiencias en las escuelas son asimismo anticipadas por los proyectos institucionales, por la planificación conjunta de docentes de un mismo ciclo escolar o área del currículum, por los planes de enseñan- 
za que realizan los maestros para sus clases, por las guías didácticas que elaboran especialistas.

El mundo escolar es sin duda unos de los espacios sociales más observados y controlados. Como vengo señalando, existen muchos dispositivos escolares que han oficiado y ofician como mecanismos eficaces a la hora de prescribir el acontecer y el ritmo de su actividad. Sin embargo, la vida escolar no cobra sentido si no es experimentada, si no es contada y recreada por los que a través de sus prácticas la re-producen cotidianamente, si el currículum no es vivido y re-elaborado por aquellos que mediante sus enseñanzas y aprendizajes llevan a cabo la tarea de la transmisión cultural en la escuela (DUBET Y MARTUCCELLI, 1998). Los proyectos educativos para los sistemas escolares no tendrían ningún efecto sobre las experiencias escolares de los estudiantes si los docentes no los adecuaran a sus expectativas, los ajustaran a sus propias visiones de los problemas, los rediseñaran a la escala particular de sus establecimientos, comunidades y estudiantes, los dijeran con sus propias voces y los escribieran con sus propias palabras (GOODSON Y WALKER, 1998).

Esta persistente recontextualización de los mandatos públicos para la formación de las nuevas generaciones hace que las prácticas escolares estén cargadas de sentidos muy diversos para quienes las hacen. Los sucesos escolares se entremezclan con las historias, proyectos y circunstancias de quienes lo transitan; son condicionados por ellos y, a la vez, tienen influencia sobre ellos. Por eso, lo que acontece en las escuelas tiene que ver casi siempre con lo que les sucede a docentes y estudiantes, con los significados particulares que les otorgan a sus prácticas y vivencias, con las experiencias cifradas por vivir en un tiempo y lugar particulares y bajo circunstancias sociales que, aun con rasgos similares, son irrepetibles. De allí que se pueda afirmar que, cada vez más, las biografías de las personas están afectadas por su paso por la escuela; pero también que éstos sólo cobran vitalidad y sentido, se actualizan y adquieren materialidad a partir de las experiencias singulares y colectivas de los sujetos sociales que se involucran con ellos. Las decisiones que toman y las acciones que realizan los docentes en relación con todas estas cuestiones, por ejemplo, nos remiten a aquellos aspectos que constituyen sus diversos itinerarios de formación: todos los elementos de una colección que reúne las experiencias de formación, comprensiones, prácticas e intercambios que hicieron posible que llegaran a ser los docentes que son hoy (HUBERMAN, 2000). 
Entonces, más allá de la compleja organización de los sistemas escolares, una parte significativa de las acciones humanas que se despliegan cotidianamente en las escuelas surgen o se "improvisan" en la dinámica misma de la vida escolar. No fueron objeto de planificación alguna y, muchas veces, forman parte de las consecuencias no deseadas de las intervenciones educativas sistemáticas. Aún en las ocasiones en que la actividad escolar pretenda ser prescrita de forma unívoca, el encuentro pedagógico entre docentes y alumnos siempre estará atravesado por la incertidumbre. De manera planificada o no, los docentes y los alumnos construyen en la escuela numerosas experiencias cargadas de significado y valor para ellos que, en cierto modo, expresan biográficamente el sentido de la escuela en un determinado momento y lugar. Es en el espacio que se abre entre la prescripción y la práctica donde las tareas de la transmisión y recreación culturales de la escuela cobran un carácter situado, territorial y coloreado por las luces, sombras y matices que les otorgan los actores escolares cuando las viven.

\section{Narrativa docente, memoria pedagógica y currículum en acción}

Por ser espacios sociales densamente significativos, las escuelas están surcadas por discursos que dan una dimensión y una temporalidad humanas a su sentido histórico. Algunos de esos discursos son "oficiales": están dichos y escritos en el lenguaje formalizado que requieren la administración de los sistemas educativos. Se presentan como textos asépticos, científicamente ponderados y técnicamente calibrados, que comunican a las escuelas las expectativas públicas para la escolarización (o para un sector de ella) en un tiempo histórico y un espacio geográfico dados. Y para ganar en eficacia normativa, tratan de reducir la polisemia en sus enunciados, minimizar las interpretaciones alternativas y referenciar en términos operativos los resultados de la acción que prescriben. Otros discursos, en cambio, son relatos que se cuentan al ras de las experiencias que tienen lugar en las escuelas: durante la enseñanza, pero también en los recreos, en las "jornadas de reflexión” de los docentes, en las conversaciones de viajes compartidos a la escuela. Estas historias se narran con las mismas palabras y estilos que usan los agentes de esas experiencias mientras las despliegan, según sus propias sensaciones y creencias, en función de sus 
propias convicciones y aspiraciones. Se dicen y se escuchan en el juego de lenguaje de la práctica, y están conjugadas en el espacio y en el tiempo de las experiencias educativas a las que refieren. En cierta medida, estos relatos nos muestran la otra cara del currículum, aquella que da cuenta de los elementos vitales, domésticos, del "currículum en acción" (SUÁREZ, 2000).

En efecto, las escuelas están cargadas de historias y los docentes muchas veces son a un mismo tiempo sus narradores, los personajes protagónicos de sus tramas y los autores de sus relatos. En ese narrar y ser narrados permanentes, recrean el sentido de la experiencia escolar y, en el mismo movimiento, reconstruyen su identidad como colectivo profesional y laboral (BULLOUGH, 2000). Al contar historias sobre sus propias prácticas pedagógicas, sobre los aprendizajes de esos alumnos y alumnas, sobre las vicisitudes a las que se enfrentan en esa escuela, sobre las estrategias de enseñanza que adoptan y los pensamientos que provocaron horas y horas de actividad escolar, los docentes hablan de sí mismos, de sus trayectorias profesionales y de las formas en que comprenden y llevan adelante su trabajo pedagógico. $\mathrm{Y}$ al hablar de sus sueños y realizaciones también nos están relatando aspectos centrales, definitorios y no documentados de la construcción escolar del currículum. Por eso, si conversamos con un grupo de docentes, podremos escuchar historias escolares que los posicionan como enseñantes que hacen escuela y la piensan en términos pedagógicos, que los interpelan como expertos del currículum en acción. Charlar con ellos puede significar una invitación a sumergirnos en relatos que narran experiencias escolares y las sutiles percepciones de quienes las vivieron. Puede ser, asimismo, una oportunidad para comprender el universo policromático de las prácticas individuales y colectivas que recrean vívidamente, en un determinado territorio, los mandatos públicos para la escuela. Contándonos sus historias escolares, los docentes narradores nos revelarán parte de las reflexiones que estas experiencias propiciaron, las dificultades que encontraron y las estrategias que adoptaron, adaptaron o inventaron para lograr ciertos aprendizajes en un grupo particular de estudiantes. Narrando las prácticas escolares que los tuvieron como protagonistas, entonces, nuestros docentes interlocutores nos estarán mostrando momentos importantes de sus propias biografías profesionales, nos confiarán sus perspectivas, expectativas e impresiones acerca de lo que consideran una buena práctica de enseñanza, el papel de 
la escuela en la sociedad contemporánea (o mejor, en ese pueblo o en aquella localidad), sus propios lugares en ella, los aprendizajes de sus estudiantes, los criterios de intervención pedagógica, curricular y docente que utilizan, los supuestos que subyacen a las formas con que evalúan los desempeños de los estudiantes y los suyos propios, las interpretaciones que elaboraron bajo la forma de relatos de los contenidos del currículum (GUDMUNDSDOTTIR, 1998).

Con sus relatos nos estarán mostrando parte del saber pedagógico que construyeron y reconstruyeron a lo largo de su carrera profesional, en la multiplicidad de experiencias y reflexiones que realizaron y realizan sobre su trabajo. Por eso, si pudiéramos sistematizar y analizar estos relatos, podríamos comprender buena parte de las trayectorias de formación de los docentes implicados, de sus supuestos e ideas sobre la enseñanza, de sus recorridos y experiencias laborales, de sus certezas y preguntas, de las influencias y anclajes ideológicos de sus convicciones pedagógicas, y también de sus inquietudes, deseos y logros. Aún más, si pudiéramos compilar y organizar el conjunto de relatos de todos los docentes, seguramente obtendríamos una historia del currículum distinta de la que conocemos, de la que habitualmente se escribe y leemos en los sistemas escolares, de la que se considera pública, verdadera, oficial. Esta otra versión de la historia de la educación sería heteróclita y dispersa (NÖVOA, 2003); en realidad, sería una multiplicidad de historias sobre el hacer escuela y el pensar en términos pedagógicos sobre ella, sobre el estar siendo docente en un determinado momento histórico y en cierto territorio. En esta versión del currículum, más próxima a una memoria pedagógica y narrativa que a un marco normativo para la "buena enseñanza", conoceríamos parte de la historia de las decisiones y prácticas que maestros y profesores protagonizan día a día y que imprime un sentido situado y personal a la experiencia social de la escolaridad.

Sin embargo, a pesar del interés que revisten para la reconstrucción de la memoria pedagógica de las escuelas, la mayoría de estas historias se pierden, se olvidan o se desechan. En muchos casos, porque no son escuchadas por quienes toman decisiones sobre los sistemas escolares, o porque son descalificadas por la racionalidad pedagógica dominante como parte de un conjunto de anécdotas triviales, pre-profesionales, que los docentes usan para contarse entre sí lo que les pasa. Para la tradición de pensamiento pedagógico centrado en la eficiencia y el control, esos rela- 
tos e historias forman parte de las dimensiones subjetivas que justamente hay que controlar para que la innovación y la mejora escolar sean posibles. Más allá de las formas que adopten, todas reformas escolares inspiradas en esa racionalidad comparten el supuesto de que el sector docente no está lo suficientemente capacitado como para manejar de manera eficaz los asuntos escolares y curriculares de la enseñanza (BOLÍVAR, 1996). Por eso, de acuerdo con esta "teoría del déficit" de la cualificación profesional de los docentes, los maestros y profesores son considerados como la variable que hay que ajustar para que la innovación de la enseñanza se realice según las orientaciones del saber técnico y experto. Currículum centralizado, capacitación sobre el déficit y evaluación cuantificada de resultados de aprendizaje son las estrategias centrales de la política de conocimiento escolar que posiciona a los maestros y profesores en un lugar subordinado, sujetado, y supuestamente sin experiencias con saber y valor pedagógico (SUÁREZ, 2005). De forma llamativa, las experiencias que dan vida a la enseñanza y los saberes pedagógicos que las piensan y recrean en su desarrollo son confinados a un lugar marginal, desdeñado, de la historia personal o "semi-profesional" de los docentes. Una parte considerable del saber práctico y reflexivo acumulado en esas experiencias escolares se naturalizan y esfuman en la cotidianeidad escolar, o bien se degradan en recurrentes anécdotas ingenuas y comentarios apresurados.

La re-creación de la memoria pedagógica de la escuela también se dificulta porque gran parte de los docentes no tienen muchas oportunidades para contarlas, escribirlas, documentarlas. Y si las tienen, los hábitos institucionales hacen que los docentes escriban a través de géneros que no permiten recuperar, ni siquiera en parte, el dinamismo, el color y la textura de lo que sucedió y les sucedió a los protagonistas de la acción. Los docentes por lo general no escriben, y cuando escriben lo hacen siguiendo pautas externas o guiones prefigurados, copiando planificaciones, completando informes solicitados por superiores jerárquicos, redactando notas de comunicación a los padres o consignas de trabajo para los alumnos. Estas prácticas de inscripción de los acontecimientos escolares son indispensables para la administración de los sistemas educativos; para la sistematización, el acopio y la disposición de información relativa a la eficacia y el rendimiento de los niveles y ciclos educativos; para la ponderación de diversas variables vinculadas con la eficiencia y el costo de los distintos dispositivos escolares implementados. Pero estos datos, infor- 
mes y documentos casi nunca ofrecen materiales sensibles para la deliberación, la reflexión y el pensamiento pedagógicos, ni para la toma de decisiones pedagógicamente informadas en los ambientes inciertos que se conforman en las aulas, ni para diseñar y desarrollar trayectos formativos de docentes que los interpelen como profesionales de la enseñanza, la pedagogía y el desarrollo curricular centrado en la escuela.

\section{Documentos escolares, documentación narrativa y formación docente}

La gestión de los sistemas educativos está saturada de procedimientos de relevamiento, almacenamiento y difusión de información sobre las prácticas escolares. Las planificaciones, los proyectos escolares, los informes de supervisores, las actas de los directivos, los legajos de los alumnos, los cuestionarios y planillas, los informes técnicos sobre resultados de evaluaciones, los informes de las investigaciones producidas por investigadores profesionales, entre otros, son soportes de modalidades convencionales de documentación que los sistemas escolares emprenden y sostienen de manera recurrente y persistente. Gran parte de los materiales documentales que producen y ofrecen es procesada, archivada e informada por las oficinas de planeamiento, y a menudo es utilizada como un insumo para la toma de decisiones.

No caben dudas de que a través del acopio y sistematización de las informaciones que proveen se pueden conocer aspectos importantes del funcionamiento de las escuelas. No obstante, la mayoría de las veces estos documentos están estructurados y se elaboran con arreglo a requerimientos administrativos y de control para el gobierno de la actividad escolar, o bien están atravesados por la racionalidad normativa-prescriptiva de la anticipación y la previsión (EZPELETA, 2005). Por eso, muchos de ellos no fueron especialmente diseñados para mostrar elementos críticos que permitan vehiculizar procesos de formación docente que hagan eje en la indagación, reflexión y deliberación pedagógicas de maestros y profesores sobre sus propias experiencias escolares. Esto se debe, entre otras cosas, a que las experiencias que sostienen y viven los docentes y alumnos tienden a ser fragmentadas, categorizadas y modelizadas a través de patrones de ponderación ajenos a la práctica escolar. Las voces y palabras de los maestros y profesores son silenciadas, distorsionadas o nega- 
das por el lenguaje técnico y burocrático y, en el mismo movimiento, sus interpretaciones pedagógicas son inhibidas, deslegitimadas o desechadas por superfluas. De esta manera, las formas a través de las cuales los docentes usualmente dan cuenta de sus prácticas muy a menudo se cristalizan en una escritura anquilosada, despojada de compromiso y belleza, y que es vivida como una carga o algo que simplemente hay que hacer.

En cambio, cuando cuentan experiencias pedagógicas relevantes para sus protagonistas, las historias escolares que narran los docentes en primera persona constituyen materiales inigualables para conocer lo que hacen, piensan y sienten quienes habitan la escuela. Mediante ellos se puede acceder a comprensiones más adecuadas sobre los modos en que se lleva adelante la experiencia escolar (BOLÍVAR Y DOMINGO, 2006; CONNELLY Y CLANDININ, 2000). Por otra parte, a través de su difusión y disposición en trayectos formativos específicos, se constituyen en materiales pedagógicos muy potentes sobre los cuales llevar adelante procesos de desarrollo profesional de docentes, tanto durante su preparación inicial como durante la implementación de diversos dispositivos de capacitación en servicio. En efecto, en tanto que narraciones que muestran las interpretaciones pedagógicas construidas al ras de la experiencia desde la perspectiva de sus productores, son materiales documentales densamente significativos que incitan a la reflexión, la conversación informada y la discusión horizontal entre docentes. Y en tanto que documentos pedagógicos que pueden ser desarrollados en espacios institucionales cercanos a las escuelas y difundidos entre los docentes, manifiestan potencialidades inéditas para la indagación y la reconstrucción de la memoria pedagógica de la escuela. Testimonian una parte importante del saber pedagógico producido por los docentes cuando despliegan e interpretan la experiencia escolar y sus propias prácticas de enseñanza. Y por eso, son fuentes inigualables para la investigación y la crítica pedagógica entre pares que esté orientada a la revisión de las miradas sobre el mundo escolar y a la tarea de nombrar de otra forma a los objetos, sucesos y procesos que tienen lugar en él (SUÁREZ, 2008).

Sin embargo, como vengo sosteniendo, por lo general esos cuerpos de saberes, relatos y experiencias no encuentran condiciones, estrategias y vías adecuadas para ser rescatados, comunicados y criticados por sus autores, o por otros docentes y actores educativos. Tampoco encuentran canales para tornarse públicos y disputar espacios en la deliberación polí- 
tica y pedagógica de la educación. De esta forma, las posibilidades de documentar aspectos "no documentados" de la práctica escolar y ponerlos al servicio de la formación docente se diluyen, y se desdibujan oportunidades importantes para desarrollar los saberes profesionales del cuerpo de enseñantes desde una perspectiva pedagógica y narrativa. La relevancia que adquiere la documentación narrativa de las propias experiencias pedagógicas por parte de los docentes radica, precisamente, en el enorme potencial que contienen sus productos, los relatos pedagógicos, para enseñarnos a interpretar el mundo escolar desde el punto de vista de sus protagonistas y para diseñar trayectos de formación docente centrados en la indagación pedagógica de esos mundos de experiencia (SUÁREZ, 2006). Pero además, porque sus dispositivos de trabajo son muy permeables para elaborar estrategias de indagación pedagógica que consoliden y constituyan progresivamente a las instituciones formadoras en centros de documentación y desarrollo pedagógicos y en nodos de colectivos y redes de docentes narradores de experiencias. En este sentido es que la documentación narrativa intenta poner a disposición tiempos, espacios y esfuerzos para que, escribiendo, leyendo, conversando y pensando entre pares en torno a relatos de experiencias, los docentes puedan mostrar, reflexionar y debatir acerca de lo que pasa y lo que les pasa en la escuela, en la formación de docentes y en el propio desarrollo profesional.

Son muchos los instrumentos, estrategias, fuentes de información y herramientas que abren la posibilidad de indagar e intervenir en las escuelas y la formación docente: entrevistas en profundidad, observaciones de distinto tipo, consultas bibliográficas, exploración del estado del arte de la cuestión, entre otras (ANDERSON Y HERR, 2005). Como argumenté en otro artículo (SUÁREZ, 2007), la etnografía escolar y la investigación biográfico-narrativa han avanzado mucho en ese sentido. No obstante, lo que intenta la documentación narrativa a través de la indagación, escritura y re-escritura de relatos por los propios protagonistas es, en primer lugar, inscribir de otro modo, sin reimpresiones de palabras puestas por los investigadores, las diversas e irrepetibles experiencias vividas en el mundo escolar y las sutiles comprensiones pedagógicas construidas por los docentes en su transcurso. Esas escrituras serán las que recreen las otras historias de la enseñanza, de la escuela y del currículum. Y si bien parten de experiencias que las pre-existen, no son su reflejo o fiel 
reproducción, sino testimonios y relatos que significan, califican y dan sentido al "haber estado alli", al haber vivido esos acontecimientos escolares, al haber reflexionado e indagado narrativamente en torno a ellos, al haber construido significaciones pedagógicas y haberles otorgado valor formativo. Los relatos pedagógicos escritos por maestros y profesores constituyen una interpretación acerca de lo acontecido y vivido por ellos que, a su vez, está abierta a distintas reinterpretaciones futuras: las propias, la de colegas, la de investigadores académicos. Precisamente por eso la documentación narrativa abre el campo de la crítica pedagógica y de la producción de conocimientos educativos, genera oportunidades para interpretaciones alternativas y dispara nuevas formas de nombrar e intervenir en la escuela.

\section{Relatos de experiencias pedagógicas: otras formas de nombrar el mundo escolar}

Pero ¿qué es lo que cuentan los relatos de experiencias pedagógicas escritos por docentes? Que un docente o grupo de docentes cuenten acerca de una experiencia implica que, al narrar, elijan ciertos aspectos, enfaticen otros, omitan, secuencien los momentos de la historia de un modo particular. De esta manera, a partir de esas decisiones tomadas por el narrador, el relato transmite el sentido que los autores otorgaron a su vivencia y las interpretaciones pedagógicas acerca de lo que sucedió. Elaborar una narración implica seleccionar episodios de lo que se vivió y configurar con ellos una cierta unidad de sentido, una trama o intriga, que otorga significado a aquello que, de otra manera, aparecería disperso y sin relaciones mutuas (RICOEUR, 1994). En el caso de estos relatos de experiencia, lo que le da cierta unidad de sentido a la intriga narrativa es la significatividad pedagógica construida por el autor en torno a los acontecimientos, escenarios, personajes y prácticas que componen y se ponen a jugar en el "mundo del texto" (RICOEUR, 2001). Cada re-escritura realizada por su autor, y apoyada en la lectura, los comentarios e interpretaciones de colegas que también están comprometidos con la documentación narrativa de sus propias prácticas docentes, supone complejas operaciones intelectuales tendientes a dotar de nuevos sentidos a los sucesos que componen la trama narrativa de la historia en cuestión. 
En rigor, esta permanente re-escritura del relato es la que torna a la documentación narrativa en un proceso reflexivo y la que potencia la mirada crítica del docente narrador: éste no va a ser el mismo que antes de escribir y de re-escribir su historia y, posiblemente, la experiencia pedagógica que relate no sea la misma que recordó antes de escribirla, o en las primeras versiones del relato. Quizás sea esa cualidad autorreflexiva lo que permita al docente narrador darle un sentido nuevo, distinto o más profundo a su propia práctica, y quizá transformarla. Ese itinerario de la narración es el que será, en definitiva, significante. La visión de sí que producen los docentes cuando narran finalmente los constituye: la identidad del sujeto es identidad narrativa, porque la pregunta por el quién eres se responde narrando una historia, contando la propia vida, relatando la propia experiencia. En este sentido, las conversaciones entre docentes acerca de sus propios relatos de experiencia pedagógica que regulan los dispositivos de la documentación narrativa, no pretenden develar lo que está oculto en los escritos o en las experiencias, sino conocer, trabajar y actuar con los significados producidos, poniéndolos en relación con los contextos en los que se produjeron y con los procesos sociales e históricos que los condicionan y los hicieron posibles; contrastándolos y tensionándolos con otras interpretaciones y saberes; tornándolos críticos; disponiéndolos hacia la transformación de la propia práctica y de la escuela.

Por otro lado, los autores del relato escriben la experiencia propia teniendo en cuenta a sus destinatarios, fundamentalmente otros docentes y actores escolares que participan en la propia "comunidad interpretativa" (PALTI, 1998). Este "trabajo hermenéutico" exige un conocimiento previo y profundo acerca de lo que desea transmitir y un trabajo intelectualmente exigente para encontrar la forma más adecuada de hacerlo, de contarlo. La subjetividad del escritor se expresa en el modo de presentación de las acciones narradas. El empleo de la primera persona en el relato escrito puede dar cuenta del proceso individual del docente, de su modo particular de organizar, conocer y aprender de la experiencia. Por lo tanto, se trata de una voz comprometida con el hacer, que se transmite a través de un relato que pretende ser al mismo tiempo reflexivo y comunicable. Así, el pronombre en primera persona representa a la vez al narrador y al protagonista de la experiencia, situando al sujeto en el lugar de constructor de su propio texto, como intérprete calificado de su propia práctica e interlocutor válido en materia de saber pedagógico. 


\section{Algunos interrogantes y potencialidades críticas}

Hasta aquí he intentado mostrar algunas de las potencialidades de la documentación narrativa de experiencias pedagógicas como una estrategia de trabajo colaborativo entre docentes, que está orientada tanto a la indagación y reconstrucción de la memoria escolar y del currículum en acción, como al desarrollo profesional entre docentes. Asimismo, a lo largo del texto he deslizado la idea de que implementar procesos de documentación pedagógica de este tipo supone una profunda redefinición de los modos habituales mediante los cuales el aparato escolar posiciona a los docentes en el campo pedagógico y los convoca para llevar adelante su trabajo, capacitarse, desarrollar el currículum, vincularse con el conocimiento. También esbocé el argumento de que, por lo general, los docentes no están acostumbrados a comportarse o imaginarse a sí mismos como activos productores de conocimiento o como narradores pedagógicos de experiencias escolares.

Llegados a este punto, entonces, vale la pena preguntarnos: ¿cómo es posible generar y desarrollar formas de documentación pedagógica diferentes a las convencionales, que permitan re-construir de manera significativa y comunicable los procesos de enseñanza que tienen lugar en las escuelas?; ¿cómo llevar adelante procesos de sistematización, publicación y difusión de las experiencias escolares locales con los sentidos específicos y contextualizados que los propios docentes les imprimen, para que puedan ser documentadas y dispuestas a circulación, reflexión, crítica y transformación?; ¿qué operaciones hay que llevar a cabo desde las administraciones educativas para poner en el centro de la construcción curricular a las experiencias de enseñanza de los docentes y a los modos narrativos que usan para darles sentido, organizarlas y contarlas?; ¿a través de qué recursos y soportes hacer públicamente disponibles esos espacios y tiempos de la vida escolar y de las biografías profesionales de los docentes? En definitiva, ¿qué hacer para que algo diferente suceda con aquello que saben y hacen en las escuelas los docentes?

Contestar estas preguntas implicaría desarrollar un programa de investigaciones sobre la formación docente y la narrativa pedagógica, cuestión que excede los objetivos de este artículo. Por ahora, vale la pena anticipar que sólo en el sentido de que "algo diferente suceda" con los docentes y sus saber pedagógico, la propuesta de documentar narrativa- 
mente las experiencias se presenta como innovadora. No pretende imponer una nueva ola de innovación didáctica a las escuelas; ni proveer a los docentes de materiales actualizados para la enseñanza; ni proponerles estrategias para la "buena enseñanza" construidas por especialistas. Se propone, más bien, innovar en las formas de interpelar a los docentes para la producción coparticipada de conocimiento pedagógico, en las estrategias montadas para su desarrollo profesional y en las modalidades de gestión de los sistemas educativos para que la memoria pedagógica de la escuela pueda ser reconstruida, objetivada, difundida, criticada. Se trata, en resumen, de poner en el centro del escenario escolar y curricular a los docentes, sus experiencias de enseñanza, su saber práctico y sus narraciones pedagógicas, a través de estrategias de documentación que permitan sistematizar y tornar públicamente disponibles los aspectos hasta ahora "no documentados" de los procesos pedagógicos que tienen lugar en las escuelas. La propuesta se basa en disponer y regular otras formas de trabajo pedagógico entre que brinden no sólo la posibilidad de anticipar, sino también de volver reflexivamente sobre lo hecho y vivido, usando la escritura narrativa como una vía para la interpretación, crítica y transformación de la propia práctica.

La cuestión radica entonces en cómo lograr implementar efectivamente una estrategia de indagación pedagógica que incursiona en lo inédito, en lo silenciado, en lo aún no descrito ni nombrado, aun cuando los hábitos institucionales tienden a configurar condiciones de enunciación tendientes a la redundancia, la repetición y la confirmación de un campo de visibilidad y de verdad (DA SILVA, 1997). Por eso, el registro, la sistematización escrita, el acopio y la difusión pública de experiencias y saberes pedagógicos contados a través de la palabra de los docentes constituyen, al mismo tiempo, una tentativa por reconstruir críticamente el currículum escolar, un programa para el desarrollo profesional docente entre docentes, y una propuesta político pedagógica para la movilización de maestros y profesores en el campo educativo. Al estimular procesos de escritura, lectura, reflexión e interpretación pedagógicas de las propias experiencias escolares de los docentes, se espera no sólo acopiar y difundir un corpus de documentos distintos a los habituales, sino también hacer posibles experiencias de recreación de saberes que signifiquen una contribución para el cambio de las prácticas pedagógicas de la escuela. Como puede apreciarse, en este caso la innovación pedagógica se inclina 
por potenciar la productividad cultural de los docentes y, en ese mismo movimiento, los afirma como protagonistas de la vida escolar y de la producción de conocimientos sobre ella. No obstante, a la vez que promueve el cambio, se reconoce en la tradición pedagógica, y recupera de ella elementos dinámicos y estratégicos para tensionarlos y re-construirlos.

La propuesta, entonces, consiste en habilitar otros espacios, tiempos y condiciones políticas e institucionales para pensar y actuar sobre la escuela y hacer posibles otras relaciones de saber y de poder entre los actores de los sistemas educativos, para comprender y problematizar aspectos de la vida escolar que las estrategias de intervención vigentes no tienen presentes. Esto significa, entre otras cosas, revalorizar el papel de los maestros y profesores en la innovación de la enseñanza, posicionarlos en el campo pedagógico como activos productores de saberes y dejar atrás las modalidades de capacitación ideadas desde el supuesto del déficit de cualificación y los estilos de gestión centralizados y verticalistas. Además, a través de colectivos y redes de docentes y escuelas trazadas por la circulación pública de los documentos pedagógicos producidos en el marco de sus dispositivos de trabajo colaborativo, la propuesta se orienta a constituir y desarrollar una comunidad de docentes narradores de experiencias pedagógicas que se movilicen cognitiva y políticamente. Esto es, una comunidad de prácticas y discursos que no quede atrapada por las pretensiones de control externo, sino que esté basada en, y se desarrolle a través de, las relaciones horizontales entre sus miembros; un colectivo de docentes narradores movilizado por el cambio pedagógico en la que sean posibles las diferencias y disidencias entre comprensiones e interpretaciones en torno a algo que sin embargo permanece común y compartido: el mundo escolar y las prácticas docentes. Una comunidad de enseñantes que habilite otras formas de "alfabetización docente": nuevas formas de escribir y de leer ese mundo escolar a través de un lenguaje propio, desde las propias perspectivas, entre ellos, pero que tensionen sus verdades ciegas, de-construyan los prejuicios y proyecten sobre él nuevos horizontes, posibilidades y oportunidades de conocimiento, formación y acción pedagógica. Documentar experiencias pedagógicas tiene como propósito hacer posibles textos narrativos escritos por maestros y profesores, tornarlos públicamente disponibles, ponderar el saber de los docentes, deconstruirlo, reconstruirlo, proyectarlo. En la medida en que estas cuestiones no son habituales, ni están habilitadas en los espacios escolares, 
resulta necesario crear ciertas condiciones políticas e institucionales para que los docentes puedan efectivamente indagar, reflexionar y comunicar a través de la narrativa las experiencias escolares.

\section{Consideraciones sobre el saber pedagógico}

Antes de concluir con el análisis de algunas implicancias intelectuales y políticas de la documentación narrativa, me parece pertinente aclarar qué quiero decir cuando me refiero al saber pedagógico, sobre todo cuando aludo al construido durante y en torno a la experiencia escolar y, más específicamente aún, cuando quiero señalar al saber pedagógico reconstruido narrativamente por los documentos escritos y editados por docentes a través de estrategias de indagación cualitativas, interpretativas y participativas. En primer lugar, cabe anticipar que con esta denominación no me remito a toda la serie de conocimientos y saberes que tienen lugar en el mundo escolar y que constituyen partes medulares de su cultura (como por ejemplo los conocimientos disciplinares que constituyen el currículum escolar, o los conocimientos administrativos implicados en la organización y dinámicas burocráticas del aparato escolar), sino a una forma de saber muy específica dentro de ese conjunto. Una forma de saber que refiere a lo que algunos autores denominan "cultura escolar empírico práctica", para diferenciarla de la "cultura científico técnica" y de la "cultura organizacional burocrática", que también constituyen la cultura escolar (EZPELETA, 2005).

Cuando menciono al saber pedagógico me refiero a un saber irreductible, específico, acerca de la enseñanza y el aprendizaje y, en particular, acerca de las posibilidades que tienen los enseñantes y los alumnos, en tanto sujetos pedagógicos, para enseñar y para aprender en contextos particulares y en ámbitos institucionales concretos, surcados por presiones y límites de diverso tipo (sociales, políticos, económicos, culturales), como lo son las escuelas o la instituciones formadoras de docentes. Un saber que muchas veces los docentes reciben y otras tantas producen o recrean, y que habla sobre los sujetos de la educación y acerca de sus diferentes y desiguales condiciones y oportunidades (intelectuales, técnicas, políticas) para encarnar experiencias pedagógicas que, por algún motivo, resulten significativas y dignas de ser comunicadas a otros y aptas para 
engrosar y cualificar la memoria pedagógica de la escuela. Me estoy refiriendo, entonces, a una forma de saber cuya construcción, circulación y apropiación por parte de los docentes y de los educadores en general tendrá consecuencias diversas sobre las modalidades más o menos democráticas que adopten las escuelas u otras instituciones educativas para formar a sus alumnos y alumnas (CONTRERAS, 1997).

Se trata, en definitiva, de un saber que da cuenta de lo que sucede pedagógicamente en las escuelas y de lo que les sucede a sus actores cuando las transitan y hacen. Dicho de otra manera, éste es un saber situado, contextualizado, construido en territorio o reproducido casi siempre narrativamente por los docentes y, por esto mismo, un saber que escapa a las generalizaciones y enunciados formalizados que pretenden ofrecer los modelos ortodoxos de conocimiento científico y técnico (KINCHELOE, 2001). Por eso, éste es un saber que es remiso a las formas de validación y legitimidad que pretenden imponer las tradiciones del pensamiento formal y científico-disciplinar (SANTOS, 2003). Apoyada en esa especificidad y como forma de rechazo a las propuestas teóricas que se inclinan a considerarlo como un conocimiento objetivo, neutral, despojado de subjetividad, producido por expertos y especialistas de acuerdo a patrones de ponderación científica y técnica, la documentación narrativa de experiencias pedagógicas renuncia provisoriamente a nominarlo "conocimiento", a fin de diferenciarlo respecto de otras formas de saber o conocimiento que también hablan, aunque con otro lenguaje, tono y formalización, acerca de la escuela y de los docentes.

Ahora bien, tanto lo que acontece en las escuelas y lo que les sucede a los docentes y alumnos en ellas, como las posibles interpretaciones acerca de ello que habilita el saber pedagógico, siempre están informados por determinadas imágenes y comprensiones sobre la enseñanza y el aprendizaje y, al mismo tiempo, por ciertas ponderaciones acerca de las capacidades y posibilidades para desplegarlos por parte de docentes y alumnos, en ciertos contextos y bajo determinadas circunstancias. El saber pedagógico que se construye en el mundo escolar al ras de las experiencias de sus actores es un saber que también está constituido y desplegado con arreglo a ciertas ideologías educativas fuertemente arraigadas en las tradiciones e innovaciones pedagógicas que intentan intervenir sobre él y los desempeños de sus habitantes. Como otras formas de saber, inclusive las científico-técnicas, el saber de los docentes está abigarrado de 
supuestos, creencias y convicciones muy efectivas a la hora de definir cursos de acción y prácticas diversas y, al mismo tiempo, ancladas en prácticas discursivas y comprensiones sociales de diverso tipo. Muchas veces, por ejemplo, los saberes pedagógicos de los docentes están informados en ideologías tecnocráticas de la educación, centradas en la medición de los resultados de la enseñanza, en la teoría del déficit y en el control de sus ejecutores, y que señalan a los docentes como sujetos incapacitados, débilmente cualificados, culturalmente impotentes, justamente como aquello que hay que "ajustar" o "reciclar" para que la innovación o la mejora escolares sean posibles. Son estos anclajes ideológicos los que estarían colaborando a que los propios maestros y profesores configuren sus prácticas docentes de determinada manera y se piensen a sí mismos como meros receptores y ejecutores de las líneas directrices que define y proyecta el saber experto y especializado. De esta manera, conjugados en términos pedagógicos y organizacionales, difícilmente propicien condiciones políticas, institucionales y técnicas para que el saber que circula, se produce, se reproduce y recrea en el aparato escolar por parte de maestros y profesores alcance visibilidad, estatuto público y, en ese movimiento, pueda ser deconstruido y reconstruido en sus elementos más dinámicos y transformadores (CHERRYHOLMES, 1999). Para eso, el conjunto de esos elementos formados de manera regular por las prácticas discursivas de los docentes, requiere ser:

Objetivado, ya que la mayoría de las veces es un saber tácito, silencioso, o silenciado por las modalidades tecnocráticas o centralizadas de gobierno y gestión escolar, o bien alcanza objetivaciones lábiles y efímeras como las que permite el discurso oral en las conversaciones informales, y esto limita su circulación en contextos más amplios restringiendo las posibilidades de indagación, reflexión y crítica por parte de los docentes y de los investigadores. Para que propicie esas prácticas, el saber pedagógico requiere inscribirse sobre soportes perdurables, como la escritura o la video-filmaciones, que permitan fijarlo provisoriamente, tornarlo visible y plausible de lecturas y análisis recurrentes y sistemáticos.

Sistematizado, reorganizado, ya que también adquiere formas muy diversas, heterodoxas e híbridas, verdaderas mezclas de saberes, creencias, convicciones, comprensiones y preguntas de todo tipo, o se organiza de acuerdo a criterios eficientistas y ajenos a las preocupaciones pedagógicas de los docentes a través de categorías extrañas para los sujetos de la 
acción. Las operaciones de sistematización de este saber requieren definir sus categorías de organización con arreglo a los "núcleos de sentido" propios del saber pedagógico, lo que supone desde el principio un complejo proceso interpretativo por parte de docentes e investigadores.

Publicado, en la medida en que muchas veces queda circunscrito al ámbito privado e íntimo de sus productores, o se genera y recrea en ámbitos restringidos, familiares, de pocos docentes, y de esta forma se limita su difusión y circulación entre colectivos más amplios y plurales de actores educativos. Por otra parte, la disposición pública de las objetivaciones desarrolladas por los docentes sobre ese saber (relatos, videos u otras inscripciones comunicables) supone una serie de operaciones que van mucho más allá de la mera circulación y disponibilidad. Implica la autorización de los docentes como productores legítimos de saber y como agentes de enunciación, y habilita a que la valoración y crítica de sus enunciados escape de los criterios limitantes que evidencia el saber experto y especializado.

Debatido, conversado, desafiado, para que no se presente como la única opción discursiva y cognitiva posible, soslayando o descalificando otras posibilidades y formas de saber y sus potencialidades para interpretar y colaborar a transformar las prácticas pedagógicas y escolares. La conversación entre docentes en torno a las comprensiones e interpretaciones pedagógicas puestas en juego y objetivadas en ese saber facilita la identificación y reconstrucción de alternativas, la confrontación dialógica de perspectivas y la multiplicación de puntos de vista acerca de los que pasó y les pasó a los sujetos de la experiencia pedagógica en cuestión.

Criticado, deconstruido, ya que para favorecer su circulación y apropiación conciente por parte de los docentes y demás actores educativos resulta necesario dar cuenta y desmontar las penetraciones e influencias ideológicas que también colaboraron a constituirlo. La crítica pedagógica resulta, de esta manera, una operación estratégica, fundamental, a la hora de discernir los elementos potencialmente transformadores de ese saber de aquellos que se encuentran anclados en supuestos limitantes de las prácticas docentes y de la experiencia escolar.

Reconstruido, de acuerdo a criterios pluralistas y mecanismos participativos que colaboren en la reorganización crítica de ese saber y de las prácticas pedagógicas que inspira. La reconstrucción del saber pedagógico elaborado por los docentes al ras de sus experiencias escolares supone 
las operaciones anteriormente descriptas (se monta sobre los resultados de la objetivación, sistematización, publicación, debate y crítica), y se proyecta como transformadora de las prácticas docentes en la medida en que logra contextualizarlas histórica y socialmente y nombrar a los objetos, agentes y procesos del mundo escolar de otra manera, con nuevas palabras y con otro sentido, pero sin abandonar el lenguaje de la práctica. La reconstrucción crítica y colectiva del saber pedagógico se orienta, de esta forma, hacia la ampliación de las oportunidades para que el mundo escolar y las prácticas docentes, ahora informadas por ese saber pedagógico reconstruido, se constituya en una experiencia cultural valiosa para todos los alumnos y alumnas.

\section{Implicancias intelectuales y políticas}

Este proceso de objetivación, sistematización, publicación, debate, crítica y reconstrucción del saber pedagógico constituye uno de los objetivos estratégicos de la documentación narrativa de experiencias pedagógicas (SUÁREZ, 2007). Y en cierta medida, también es decisivo en el proceso de reformulación de la tradición crítica en pedagogía de acuerdo a "criterios epistemológicos críticos, hermenéuticos y pragmáticos" en la que esta estrategia de investigación-formación-acción está comprometida e impulsa (SANTOS, 2008). No obstante, cabe aclarar que su desarrollo como modalidad de formación y desarrollo profesional, como propuesta curricular y como dispositivo de indagación pedagógica coparticipada, supone serias implicancias intelectuales y políticas para el campo educativo. Fundamentalmente porque su implementación tiene impacto directo en el trabajo pedagógico cotidiano que llevan a cabo los docentes en las escuelas y porque presiona para su re-posicionamiento en las relaciones de saber y de poder que configuran el campo pedagógico y las jerarquías y autorizaciones del aparato escolar. Las implicancias intelectuales son relativamente conocidas: las operaciones cognitivas implicadas en la producción crítica de saberes de este tipo son complejas, de orden superior, y se orientan a redefinir los modos en que se produce, circula, distribuye y usa el conocimiento pedagógico. Ese trabajo intelectual exigente se vincula con modalidades bastante sofisticadas de investigación social y educativa cualitativa, etnográfica, (auto)biográfica y narrativa, y con pro- 
cedimientos metodológicos propios de la investigación participativa o colaborativa y de la "investigación-acción docente" (ANDERSON, 2007). De esta forma, el dispositivo y las acciones de indagación pedagógica que llevan delante de manera conjunta docentes e investigadores en una conversación teórica y metodológica abierta, se articulan en función de procesos de producción de conocimiento en los que uno de los sujetos de las experiencias escolares se involucran en procesos de objetivación, sistematización, publicación, debate, crítica y reconstrucción de sus propias prácticas y saberes.

Existen muchos modelos diferentes de investigación educativa de este tipo, y también bastantes y distintas experiencias registradas y difundidas ${ }^{1}$. Casi todas plantean, básicamente, estrategias tendientes a tornar discursivo ese saber silencioso, construido al ras de la experiencia escolar por sus actores, pero con pocas oportunidades para tornarse públicamente disponible y por ende ser potencialmente evaluable tanto en el espacio público como en el especializado. Y también todas ellas comparten el supuesto y la recomendación metodológica de que los docentes deben participar activamente (aunque en distinto grado, según la tradición de investigación de que se trate) en los procesos de inscripción, publicación, conversación, deliberación, deconstrucción y reconstrucción de saberes pedagógicos y comprensiones sociales referidas a la experiencia escolar.

Por su parte, las implicancias políticas que proyectan estos procesos están menos exploradas y, al mismo tiempo, son más difíciles de lograr, fundamentalmente porque tienen que ver con la generación y el sostenimiento de condiciones institucionales y normativas para que la compleja experiencia cognitiva de la documentación narrativa tenga lugar. Estas implicancias políticas son menos tenidas en cuenta, y justamente ese olvido conspira en contra de la posibilidad de llevar adelante procesos de producción colaborativa de saber pedagógico. Esto sucede aun cuando en el campo pedagógico se habiliten prácticas de investigación pedagógica cualitativa más o menos participativas para los docentes. No se trata tan sólo de un problema de enfoques de investigación o una dificultad de orden metodológico; es fundamentalmente un problema de política de conocimiento o de "epistemología política", una cuestión que tiene que ver con la generación de jerarquías para la producción del saber pedagógico, con la distribución de los sujetos vinculados con ese saber en rela- 
ciones de poder y subordinación, y con la generación de marcos de legitimidad para esas jerarquías y las posiciones que ocupan en ellas los diferentes sujetos del campo pedagógico.

Promover y sostener condiciones institucionales y políticas para la producción autogenerada o coparticipada de saberes pedagógicos por parte de los docentes implica, antes que nada, cambiar las "reglas de juego" del campo educativo y, particularmente, las del aparato escolar. Dicho más crudamente, no es posible desarrollar estrategias de documentación narrativa si no existen ya dadas ciertas condiciones mínimas para la enunciación y la recepción de los relatos de experiencia escritos por los docentes narradores. Y cambiar las reglas de juego, como sabemos, es difícil, ya que supone una fuerte corriente de destitución y de reinstitución en ámbitos institucionales bastante refractarios a las transformaciones radicales. Requiere entre otras cosas re-posicionar a los docentes en la trama de relaciones de poder y de saber del aparato escolar y promover nuevas relaciones, más horizontales y poderosas, de los docentes con los administradores, los equipos de coordinación y supervisión, los capacitadores y, sobre todo, con los denominados "especialistas" y "expertos" que en la actualidad controlan el discurso pedagógico y la validación del conocimiento educativo. Se trata, en síntesis, de generar una nueva configuración del poder y del saber en el aparato escolar y en el campo educativo, y esto es mucho más complejo y difícil de lograr que involucrar ocasionalmente a los docentes en procesos de investigación que escuchen, interpreten y conversen con sus saberes y discursos.

Por el lugar que ocupan en la escuela y en el desarrollo de las experiencias pedagógicas que tiene lugar en ellas, en principio, los docentes están en potenciales excelentes condiciones para incorporarse activamente en la producción de ese saber y para, en ese proceso, constituirse en actores de la experiencia escolar y autores calificados de la construcción escolar del currículum. No obstante, y como ya abundante literatura denuncia, los docentes están "interferidos" en sus funciones y capacidades intelectuales y políticas (BATALLÁN, 2007); esto es, son interpelados como sujetos incapaces, mal formados, con una pobre dotación de capital cultural, por las políticas de conocimiento y subjetividad hegemónicas vigentes en el sistema escolar y en el campo educativo. $\mathrm{Y}$ son posicionados, y generalmente ellos mismos se posicionan, en el lugar de la carencia, la subordinación al "saber experto", el silencio y el estereotipo. El discur- 
so y la agenda de las reformas educativas de los '90 en Argentina y en gran parte de América Latina sin dudas colaboraron en consolidar de estas relaciones jerárquicas de saber y de poder en el aparato escolar. Los programas reformistas dirigidos a la supuesta mejora de la "calidad educativa" (básicamente, la reforma centralizada del currículum, los operativos también centralizados de evaluación de los resultados de los aprendizajes de los alumnos y la capacitación masiva y extendida de docentes) contribuyeron al confinamiento de los docentes en esas posiciones subordinadas, más que a lograr de ellos agentes capacitados para el cambio. Se montaron sobre dispositivos de gobierno y gestión escolares que reconcentraron y recentralizaron las posiciones enunciativas del discurso pedagógico legítimo y, de esta manera, contribuyeron a cristalizar modalidades de intervención verticalistas, centradas en el saber experto, especializado y científico-técnico, orientadas por el control tecnocrático y asentadas en jerarquías que fijan posiciones de sujeto diferenciadas respecto de la capacidad para producir saberes legítimos. En otras palabras, colaboraron en la descredibilización de los docentes, en la desacreditación de sus saberes y experiencias pedagógicas y en la configuración de relaciones y condiciones institucionales y políticas que dejan márgenes muy estrechos para su participación activa en la producción sistemática y validada de conocimientos pedagógicos. Es importante agregar inmediatamente que estas condiciones de producción, acceso y apropiación del saber pedagógico ya estaban instaladas con fuerza en la cultura burocrática y administrativa del mundo escolar, así como recomendadas por ciertas ideologías pedagógicas tecnicistas que se incorporaron activamente a la cultura escolar, sobre todo a partir de la década de los '60. Y que, en cierta forma, este anclaje institucional e ideológico puede ser considerado como uno de los elementos que jugaron a favor del relativo éxito y aceptación inicial en el campo educativo de las reformas educativas de la década de los '90.

Afortunadamente, en los últimos años en América Latina existen algunos indicios de tendencias emergentes que, aunque inestables y todavía inarticuladas, parecen estar orientadas a revertir progresivamente esta situación. Como señalé, cada vez hay más iniciativas de intervención e investigación pedagógicas tendientes a involucrar de manera activa a los docentes en la producción y reconstrucción crítica de sus saberes pedagógicos. Muchas de ellas indagan, precisamente, en las implicancias intelectuales y cognitivas de ese involucramiento y esa participación. Estas expe- 
riencias coparticipadas de producción de saber pedagógico se llevan a cabo fundamentalmente en universidades públicas y, en particular, en algunas universidades pedagógicas del subcontinente, pero también en instituciones de formación docente, centros de investigación autónomos y movimientos político pedagógicos impulsados por organizaciones, redes y colectivos de docentes. Pero también existen cada vez más experiencias de gobiernos educativos centrales y locales que orientan gran parte de su política educativa a coordinar acciones y a generar las condiciones institucionales para que esas experiencias abiertas, pluralistas y democráticas de producción de saber pedagógico sean posibles.

No obstante, esta tarea simultáneamente política y cultural es compleja e involucra un doble desafío para los gobiernos de los sistemas escolares. En primer término, implica diseñar y llevar a la práctica políticas educativas activas e integrales, centralmente orientadas a revertir las tendencias descalificantes de la reforma educativa para con los maestros y profesores, pero también dirigidas a desmontar esos otros anclajes del aparato escolar que, aún antes de la reforma de los '90, ya venían confinando a los docentes a la mera ejecución de recetas técnicas elaboradas por expertos y subordinándolos a las jerarquías del control burocrático y a los instrumentos de gestión escolar. En resumen, uno de los desafíos de los gobiernos educativos democráticos es impulsar políticas educativas tendientes a desarticular las falacias y mostrar las implicancias políticopedagógicas de las ideologías educativas de la imposibilidad, la desconfianza y el control técnico ya instaladas (y muchas veces naturalizadas) en las prácticas y estructuras escolares. En segundo lugar, el desafío de los gobiernos educativos consiste en promover y sostener políticas de conocimiento (pedagógico) y de subjetividad (docente) que interpelen y ayuden a re-posicionar a los maestros, profesores y demás actores del campo pedagógico de otra manera, de una forma más creativa y productiva y menos sujeta a las miradas y palabras autorizadas del exterior. Políticas que al mismo tiempo los autoricen y habiliten como actores medulares en las tareas intelectuales vinculadas con la producción, crítica y re-construcción del saber pedagógico de la escuela y como partícipes en la construcción misma de las condiciones institucionales y políticas para la creación, difusión y circulación pública de ese saber. Políticas que pongan en juego formas de interpelación hacia los docentes que los autoricen en términos políticos, pedagógicos y técnicos para involucrarse activamente en la 
reconstrucción del saber profesional y específico acerca de las prácticas escolares y para ponerlo en tensión mediante la conversación y debate públicos.

Como se desprende de lo anterior, el Estado y las políticas públicas tienen un papel estratégico en este proceso de reforma de la escuela. Pero la reconstrucción democrática de las políticas públicas en este sentido también requiere de una fuerte movilización social, política y cultural de los actores educativos. La tarea implicada en la formulación de una nueva política de conocimiento para la escuela y los docentes necesita de una fuerza social y política que vaya más allá del gobierno escolar estatal, y que sea capaz de presionarlo en función de sus objetivos democratizadores. Por eso, es políticamente importante y estratégico atender, conocer, habilitar y promover, también desde el Estado y la administración de los aparatos educativos, las experiencias y formas autoorganizadas de producción colectiva de saberes y conocimientos pedagógicos como muchas de las que se vienen desarrollando, aunque de manera incipiente, en diferentes países y contextos de América Latina. Sin lugar a dudas, los gobiernos y otros actores educativos aprenderían mucho de esos movimientos político-pedagógicos, que generalmente involucran modalidades de organización social e intelectual de los docentes y demás educadores íntimamente relacionadas con otros movimientos sociales, y que la mayoría de las veces combinan procesos de formación horizontal entre pares, estrategias de investigación acción y participante sobre las propias experiencias y prácticas pedagógicas, modalidades de desarrollo curricular centrados en la experiencia escolar y en la reconstrucción narrativa de las prácticas pedagógicas, junto con movilizaciones políticas y sociales a favor de la educación pública y la democratización de la escuela.

Todas esas experiencias de movilización político pedagógica son muy diversas entre sí y todavía están escasamente articuladas. Son poco conocidas y aún no forman parte del imaginario político pedagógico de la escuela. Pero ya algunos gobiernos educativos han comenzado a conversar con ellas y a explorar formas de articulación en el plano de las políticas públicas para el campo educativo y escolar. Como la documentación narrativa, son experiencias centradas en la reconstrucción y difusión del saber pedagógico puestos en juego por los docentes durante la experiencia escolar, y suponen la indagación crítica y la conversación pluralista y abierta entre esos saberes y experiencias y sus protagonistas. Sin lugar a 
dudas, articuladas o incorporadas a las políticas educativas estatales, estructuradas como políticas de Estado, podrían colaborar en mucho en la amplificación de la creatividad didáctica de los docentes y en la profundización de la imaginación pedagógica de las escuelas. 


\section{REFERENCIAS}

ANDERSON, Gary; HERR, Kathryn. The action research dissertation. A guide for students and faculty. Londres: Sage, 2005.

ANDERSON, Gary. El docente-investigador: investigación-acción como una forma válida de conocimientos. In: SVERDLICK, I. (comp.) La investigación educativa. Una herramienta de conocimiento y acción. Buenos Aires: Novedades Educativas, 2007. p. 47-70.

BATALLÁN, Graciela. Docentes de infancia. Antropología del trabajo en la escuela primaria. Buenos Aires: Paidós, 2007.

BOLÍVAR, Antonio. El lugar del centro escolar en la política curricular actual. Más allá de la reestructuración y de la descentralización. In: PEREYRA, M. et al. Globalización y descentralización de los sistemas educativos. Fundamentos para un nuevo programa de la educación comparada. Barcelona: Pomares-Corredor, 1996. p. 123-184.

BOLÍVAR, Antonio; DOMINGO, Jesús. La investigación biográfica y narrativa en Iberoamérica: Campos de desarrollo y estado actual. Forum: Qualitative Social Research, v. 7, n. 4, Art. 12. Septiembre de 2006. Disponível em <http://www.qualitative-research.net/fgs-texte/4-06/06-4-12-s.htm/>.

BULLOUGH, Robert. Convertirse en profesor: la persona y la localización social de la formación del profesorado. In: BIDDLE, B.; GOODSON, I. (Eds.). La enseñanza y los profesores. La profesión de enseñar. Barcelona: Paidós, 2000. p. 99-166.

CHERRYHOLMES, Cleo. Poder y crítica. Investigaciones postestructurales en educación. Barcelona: Pomares-Corredor, 1999.

CONNELLY, F. Michael; CLANDININ, D. Jean. Narrative inquiry. Experiencie and story in qualitative research. San Francisco: Jossey-Bass, 2000.

CONTRERAS DOMINGO, José. La autonomía del profesorado. Madrid: Morata, 1997.

DA SILVA, Tomaz Tadeo. Descolonizar el currículo: estrategias para una pedagogía crítica. In: GENTILI, P. (comp.) Cultura, política y currículo. Ensayos sobre la crisis de la escuela pública. Buenos Aires: Losada, 1997. p. 63-80.

DUBET, Francois; MARTUCCELLI, Danilo. En la escuela. Sociología de la experiencia escolar. Buenos Aires: Losada, 1998.

EZPELETA, Justa. Entre la gestión del cambio y el cambio de las prácticas. In: ANDERSON, Gary et al. Escuela: producción y democratización del conocimiento. Ciudad de Buenos Aires: Secretaría de Educación - GCBA, 2005. p. 25-40.

GOODSON, Ivor; WALKER, Rob. Contar cuentos. In: Mc EWAN, H.; EGAN, K. (comps.) La narrativa en la enseñanza, el aprendizaje y la investigación. Buenos Aires: Amorrortu editores, 1998. p. 260-273.

GUDMUNDSDOTTIR, Sigrun. La naturaleza narrativa del saber pedagógico sobre los contenidos. In: Mc EWAN, H.; EGAN, K. (comp.) La narrativa en la enseñanza, el aprendizaje y la investigación. Buenos Aires: Amorrortu editores, 1998. p. 52-71.

HUBERMAN, Michael y otros. Perspectivas de la carrera del profesor. In: BIDDLE, B.; GOODSON, I. (Eds.). La enseñanza y los profesores I. La profesión de enseñar. Barcelona: Paidós, 2000. p. 19-98.

KINCHELOE, Joe. Hacia una revisión crítica del pensamiento docente. Barcelona: Octaedro, 2001.

NÓVOA, Antonio. Textos, imágenes y recuerdos. Escritura de 'nuevas' historias de la 
educación. In: POPKEWITZ, T.; FRANKLIN, B.; PEREYRA, M. (comps.) Historia cultural y educación. Ensayos críticos sobre conocimiento y escolarización. Barcelona: Pomares Corredor, 2003. p. 61-84.

PALTI, Elías. Giro lingüístico e historia cultural. In: PALTI, E. Giro lingüístico e historia cultural. Buenos Aires: Universidad Nacional de Quilmes, 1998. p. 19-168.

PETITAT, André. Produçao da escola, producao da sociedade. Análise sócio-histórica de alguns momentos decisivos da evolução escolar no occidente. Porto Alegre: Artes Médicas, 1994.

RICOEUR, Paul. Educación y politica. De la historia personal a la comunión de libertades. Buenos Aires: Docencia, 1994.

RICOEUR, Paul. Del texto a la acción. Buenos Aires: Fondo de Cultura Económica, 2001. ROCKWELL, Elsie. De huellas, bardas y veredas: una historia cotidiana en la escuela. In: ROCKWELL, E. (Coord.). La escuela cotidiana. México: Fondo de Cultura Económica, 1995. p. 88-102.

SANTOS, Boaventura de Sousa. Introducao a uma ciencia pós-moderna. Sao Paulo: Graal, 2003.

SANTOS, Boaventura de Sousa. Conocer desde el Sur. Para una cultura política emancipatoria. La Paz: CLACSO, 2008.

SUÁREZ, Daniel H. Currículum, escuela e identidad. Elementos para repensar la teoría curricular. In: TÉLLEZ, Magaldy (comp.) Otras miradas, otras voces. Repensando la educación en nuestros tiempos. Buenos Aires: Novedades Educativas Ediciones, 2000. p. 95138.

SUÁREZ, Daniel H. Los docentes, la producción del saber pedagógico y la democratización de la escuela. In: ANDERSON, Gary et al. Escuela: producción y democratización del conocimiento. Ciudad de Buenos Aires: Secretaría de Educación - GCBA, 2005. p. 79-88.

SUÁREZ, Daniel H. Documentación narrativa de experiencias pedagógicas. Una manera de indagar el mundo y la experiencia escolares. In: Entre maetr@s. Revista para maestr@s de educación básica. Universidad Pedagógica Nacional, v. 5, n. 15. México, p. 73-87, primavera de 2006.

SUÁREZ, Daniel H. Docentes, narrativa e investigación educativa. La documentación narrativa de las prácticas docentes y la indagación pedagógica del mundo y las experiencias escolares. In: SVERDLICK, I (comp.) La investigación educativa. Una herramienta de conocimiento y acción. Buenos Aires: Novedades Educativas, 2007. p. 71-110.

SUÁREZ, Daniel H. La tradición crítica en educación y reconstrucción de la pedagogía. In: ELISALDE, Roberto; AMPUDIA, Marina (comp.) Movimientos sociales y educación: teoría e historia de la educación popular en Argentina y América Latina. Buenos Libros, Buenos Aires, 2008. p. 193-214. 


\section{NOTA}

1 Algunas de ellas son las que tienen lugar en el marco de la Red Iberoamericana de Docentes que Hacen Investigación desde la Escuela (Red DHIE); de la Expedición Pedagógica Nacional de Colombia, que se desenvuelve en el marco del Movimiento Pedagógico Nacional, con la participación de la Universidad Pedagógica Nacional; y los Centros de Autoformación Docente (CADs) que, bajo la coordinación del Instituto de Pedagogía Popular del Perú, se desarrolla e impulsa el Movimiento Pedagógico Popular. En Argentina, cabe señalar a las experiencias de investigación participante puestas a jugar por los "talleres de investigación sobre la práctica”, diseñados y desarrollados por Graciela Batallán (2006), junto con maestros de escuela primaria, en la Universidad de Buenos Aires.

Recebido: 03/05/2010

Aprovado: $18 / 10 / 2010$

Contato:

Universidad de Buenos Ayres Faculdad de Filosofía y Letras

Puán 480, of. 327

Ciudad de Buenos Ayres - Argentina 